\title{
Aliskiren in hypertension: evidence for its potential therapeutic value
}

\author{
Doris Peter
}

\author{
Core Medical Publishing, New York, USA
}

\begin{abstract}
Introduction: Aliskiren is the first in a new class of antihypertensive drugs that inhibits the conversion of angiotensinogen to angiotensin I by renin, thereby inhibiting production of angiotensin II, the key mediator in the regulation of body fluid volume and blood pressure. Aliskiren is currently in phase III trials as monotherapy and phase II as combination therapy in patients with mild-to-moderate hypertension, and in phase II trials in patients with diabetic nephropathy.
\end{abstract}

\begin{abstract}
Aims: The aim of this review is to evaluate the emerging evidence for use of aliskiren in patients with hypertension and to predict its preliminary place in therapy in clinical outcome terms. All randomized, controlled clinical trials of aliskiren (evidence level 2) were included for analysis of efficacy with the selected outcomes of blood pressure lowering, tolerability, and adherence; all other publications were excluded.

Evidence review: The available level 2 evidence, although limited to phase II trials, suggests that aliskiren is effective at lowering blood pressure, an accepted surrogate outcome of morbidity and mortality, in patients with mild-to-moderate uncomplicated essential hypertension. Preliminary evidence suggests aliskiren is as effective as the angiotensin receptor blocker irbesartan, but more studies are needed. The available evidence also suggests that aliskiren is well tolerated and that patients exhibit good adherence to therapy. Aliskiren's effect on outcomes such as all-cause mortality, reduction in cardiovascular mortality, and reduction in cardiovascular events in patients with mild-to-moderate essential hypertension as well as in special patient populations, remains to be determined.
\end{abstract}

Clinical potential: The evidence available regarding aliskiren's effect on outcomes, including blood pressure, tolerability, and adherence, supports its use in patients with mild-to-moderate hypertension. Although there is some preliminary evidence from small pilot trials, the use of aliskiren in combination with other antihypertensives, and the use of aliskiren in other patient populations, cannot be recommended without further evidence.

Key words: aliskiren, hypertension, outcomes, evidence, renin, diabetic nephropathy

\section{Core evidence proof of concept summary for aliskiren in hypertension}

\begin{tabular}{|c|c|}
\hline Outcome measure & Emerging evidence \\
\hline \multicolumn{2}{|l|}{ Disease-oriented evidence } \\
\hline Blood pressure lowering in monotherapy & $\begin{array}{l}\text { Aliskiren as monotherapy is effective for treatment of hypertension and may be as effective } \\
\text { as an ARB }\end{array}$ \\
\hline Blood pressure lowering in combination therapy & Pilot trials demonstrate efficacy in combination with valsartan in normotensive individuals \\
\hline $\begin{array}{l}\text { Blood pressure lowering in other categories of patient (i.e. severe } \\
\text { hypertension, elderly, different races, children) }\end{array}$ & No evidence \\
\hline Renal-protective effect & No evidence \\
\hline \multicolumn{2}{|l|}{ Patient-oriented evidence } \\
\hline Tolerability & $\begin{array}{l}\text { Aliskiren is highly tolerable and is probably as well tolerated as an ARB. Useful in patients } \\
\text { who cannot tolerate other drugs, especially ACE inhibitors }\end{array}$ \\
\hline Adherence & $\begin{array}{l}\text { Aliskiren's high tolerability and adherence in phase II suggest patients will adhere to aliskiren } \\
\text { therapy to the same extent as with an ARB }\end{array}$ \\
\hline
\end{tabular}




\begin{tabular}{|ll|}
\hline $\begin{array}{ll}\text {...table continued } \\
\text { Outcome measure }\end{array}$ & Emerging evidence \\
\hline Decrease in major cardiovascular events & No evidence \\
Decrease in mortality & No evidence \\
Economic evidence & \\
Cost effectiveness & No evidence \\
\hline ACE, angiotensin-converting enzyme; ARB, angiotensin receptor blocker. & \\
\hline
\end{tabular}

\section{Scope, aims, and objectives}

Aliskiren (Novartis) is the first in a new class of antihypertensive drugs called renin inhibitors that inhibit the conversion of angiotensinogen to angiotensin I by renin. Renin inhibition blocks production of angiotensin II, a key mediator in the regulation of body fluid volume and blood pressure.

The objective of this article is to review the available evidence, limited to phase II trials and pilot trials, for the use of aliskiren in patients with hypertension, evaluating its effects on available measured outcomes including blood pressure, adherence, and tolerability. In addition, this article will provide an overview of the disease, current treatment options, and pharmacoeconomic considerations regarding antihypertensive drugs. Finally, given the available outcomes evidence a discussion of aliskiren's preliminary place in therapy will be presented.

\section{Methods}

Literature searches were conducted on January 31, March 2, and May 8, 2005 in the databases listed below. The search terms were "aliskiren" and "SPP100" with no search tags unless otherwise stated. Results were limited to English-language articles only. No date limitations were imposed unless otherwise noted.

- PubMed, www.ncbi.nlm.nih.gov/entrez, 1966 to date

- EMBASE, www.datastarweb.com, 1974 to date

- Database of Abstracts of Reviews of Effectiveness (DARE), NHS Economic Evaluations Database (NHSEED), Health Technology Assessment (HTA), www.york.ac.uk/inst/crd/darehp.htm

- NHS HTA, www.ncchta.org

- National Guidelines Clearinghouse, www.guideline.gov

- National Institute for Health and Clinical Excellence (NICE), www.nice.org.uk

- Cochrane Database of Systematic Reviews, www.cochrane.org

- Clinical Evidence, www.clinicalevidence.com

- American Society for Hypertension (ASH) abstract database, www.abstracts2view.com/ash/

After removal of duplicates a total of 28 citations were identified from PubMed, EMBASE, and ASH; no additional citations were identified from the other databases. Records were manually reviewed and 22 citations were excluded: animal studies $(n=1)$, nonsystematic reviews $(n=12)$, and citations that mentioned aliskiren but did not investigate its clinical use $(n=9)$. No systematic reviews of aliskiren have been published.
Inclusion criteria for the outcomes analysis of aliskiren used an accepted scale of hierarchy of evidence (see Editorial Information on inside back cover). All randomized, controlled clinical trials of aliskiren (evidence level 2) were included (Table 1).

\section{Introduction}

Aliskiren is an oral antihypertensive drug that inhibits the conversion of angiotensinogen to angiotensin I by renin, the first step of the renin-angiotensin system (RAS) and a rate-limiting step in the production of angiotensin II (Fig. 1). Angiotensin I is then metabolized by angiotensin-converting enzyme (ACE) and other enzymes to yield angiotensin II, a key mediator in the regulation of body fluid volume and blood pressure. Angiotensin II controls body fluid volume both directly by stimulating sodium reabsorption in the proximal tubule of the kidney, and indirectly through stimulation of aldosterone release. Angiotensin II is also a potent vasoconstrictor that acts on arterioles to increase systemic blood pressure. Inhibitors of other steps in the RAS pathway (Fig. 1), including ACE inhibitors that block the conversion of angiotensin I to angiotensin II and angiotensin receptor blockers (ARBs) that inhibit binding of angiotensin II to type I angiotensin II receptors (AT-1), are currently in clinical use as antihypertensive agents.

Research suggests that hypertension is related to vascular damage, oxidative stress, and inflammation. Angiotensin II, one of the key mediators in hypertensive disease, has been shown to act as a proinflammatory mediator that increases vascular permeability, promotes recruitment of inflammatory cells, and activates the infiltrating immune cells (Touyz 2005). Angiotensin II has also been shown to be involved in tissue repair and remodeling.

The initial development of peptides as renin inhibitors began around the same time as the development of ARBs, but problems with oral bioavailability and cost prevented the clinical

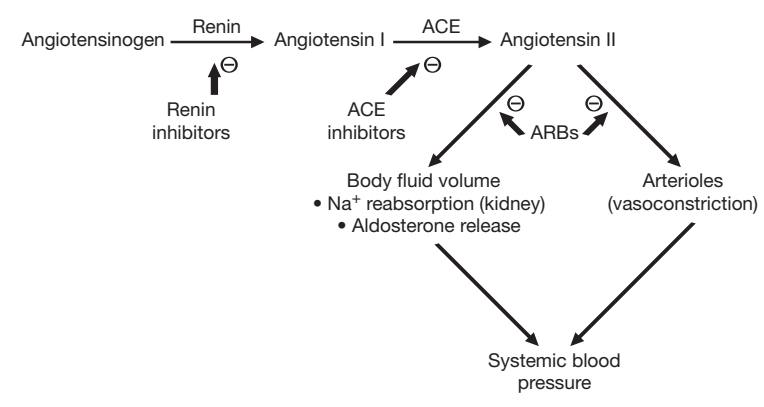

Fig. 1 | The renin-angiotensin system and pharmacotherapy 
Table 1 | Evidence base included in the review

\begin{tabular}{|lcc|} 
& \multicolumn{2}{c|}{ Number of records } \\
\cline { 2 - 3 } Category & Full papers & Abstracts \\
\hline Initial search & 26 & 1 \\
records excluded & 22 & 0 \\
records included & 4 & $1^{\text {a }}$ \\
Additional studies identified & 1 & 0 \\
Level 1 clinical evidence & 0 & 0 \\
Level 2 clinical evidence & 5 & 0 \\
Level $\geq 3$ clinical evidence & 0 & 0 \\
trials other than RCT & 0 & 0 \\
case reports & 0 & 0 \\
Economic evidence & 0 & 0 \\
\hline alncluded in the original review and later excluded because the same study was identified \\
later as a full paper. \\
RCT, randomized controlled trial
\end{tabular}

development of these earlier versions (Hollenberg \& Fisher 1995; Rongen et al. 1995; Fisher \& Hollenberg 2001). These challenges were overcome in the development of aliskiren through the use of molecular modeling to design a small molecule drug with high affinity and specificity for renin, better oral bioavailability, and a long in vivo activity that had the potential for once-daily dosing (Wood et al. 2003).

The attributes of renin inhibitors theoretically meet some of the unmet needs in the treatment of patients with hypertension. By inhibiting the first and rate-limiting step in the RAS system (conversion of angiotensinogen to angiotensin I), aliskiren may block the generation of angiotensin II more completely than ACE inhibitors because there is no other substantive pathway for angiotensin I production (Stanton 2003). In contrast, angiotensin II, the major effector regulating blood pressure, can be synthesized by alternative pathways (Wolny et al. 1997). Thus, a more complete block of angiotensin II production via renin inhibition could provide an advantage, perhaps increasing the effectiveness of monotherapy.

Aliskiren is currently in phase III trials for use as monotherapy and in phase II trials in combination with valsartan, in patients with uncomplicated mild-to-moderate hypertension. It is also being studied in phase II trials in patients with hypertension and diabetic nephropathy. Regulatory submission is expected to be filed in early 2006.

\section{Disease overview}

Hypertension is a common disease that affects approximately 50 million people in the USA and about 1 billion people worldwide (NHLBI 2004). The most common sequela of hypertension, cardiovascular disease, is also the most frequent cause of death in industrialized countries. The World Health Organization (WHO) estimates that there are 7.1 million deaths (13\% of total deaths) annually due to complications of hypertension (WHO 2002). The worldwide prevalence of hypertension is increasing; recent studies estimate that the prevalence will increase by $60 \%$, from $26.4 \%$ in 2000 to $29.2 \%$ by 2025 (Kearney et al. 2005).

Although hypertension is a worldwide problem, sample surveys from the 1990s have shown that its prevalence differs between regions of the world. For example, in North America the prevalence of hypertension is about $28 \%$ compared with about $44 \%$ in Europe (Wolf-Maier et al. 2003). A recent analysis of surveys found that the highest estimated prevalence for men was in Latin America and the Caribbean (Mexico, Paraguay, and Venezuela) and for women in former socialist economies (e.g. Slovakia); for both sexes the lowest prevalence was in Asian regions (e.g. Korea, Thailand, Taiwan) (Kearney et al. 2005).

In addition to geographic differences, the prevalence of hypertension also differs by race. For example, in the USA about $28 \%$ of Caucasians are hypertensive compared with $40-43 \%$ of African-Americans (NCHS 2004). A recent study has shown, however, that there are wide variations in hypertension prevalence in both black (14-44\%) and white (27-55\%) populations worldwide, and highlighted the importance of not overlooking environmental factors that impact hypertension prevalence rates (Cooper et al. 2005).

Some regional differences can be explained by genetic factors and population demographics. In addition to race, family history of hypertension confers significant additional risk, since the genetic heritability of hypertension is about 30\% (Agarwal et al. 2005). Age is another significant risk factor for developing hypertension. Data from the Framingham Heart Study show that the residual lifetime risk for developing hypertension in a normotensive, 55-year-old person is 90\% (Vasan et al. 2002). Obesity is also a significant risk factor.

Awareness, treatment, and control of hypertension remain significant challenges. Most people with hypertension are undiagnosed, untreated, or undertreated, despite educational campaigns and the availability of many generally well-tolerated antihypertensive drugs. In the USA, data from the National Health and Nutrition Examination Survey (NHNES) found that $30 \%$ of people with hypertension were unaware of their condition, $41 \%$ were not treated, and $66 \%$ of those with hypertension were not well controlled (NHLBI 2004). Another study among patients with hypertension found that $71 \%$ in the USA, $83 \%$ in Canada, and more than $90 \%$ in Europe were not well controlled (Wolf-Maier et al. 2004).

However, for those patients who are appropriately treated, effective blood pressure lowering has been shown to decrease the incidence of stroke by between 30 and 39\%, coronary heart disease by $20 \%$, and major cardiovascular events by $21-28 \%$ (Neal et al. 2000). In patients with stage 1 hypertension (systolic blood pressure 140-159 $\mathrm{mmHg}$ and/or diastolic blood pressure $90-99 \mathrm{mmHg}$ ), it has been estimated that a $12 \mathrm{mmHg}$ reduction of blood pressure for 10 years prevents one death for every 11 moderate-risk patients treated, while a similar blood pressure reduction in higher risk patients with cardiovascular disease and target organ damage prevents one death for every nine patients treated (NHLBI 2004). 
Table 2 | Comparison of current hypertension guidelines

\begin{tabular}{|c|c|c|c|c|}
\hline \multirow[t]{2}{*}{ Guideline } & \multirow[t]{2}{*}{ Prehypertension } & \multirow[t]{2}{*}{ Initial therapy ${ }^{a}$} & \multicolumn{2}{|c|}{ Threshold for pharmacologic intervention $(\mathrm{mmHg})$ SBP/DBP } \\
\hline & & & Uncomplicated & Special populations ${ }^{b}$ \\
\hline USA $^{\mathrm{C}}$ & Yes & Low-dose thiazide diuretic & $\geq 140 / 90$ & $>130 / 80$ \\
\hline WHO/ISH ${ }^{d}$ & No & Low-dose thiazide diuretic & $\geq 140 / 90$ & $\geq 130 / 80$ \\
\hline $\begin{array}{l}\text { European Society of } \\
\text { Hypertension/European } \\
\text { Society of Cardiologye }\end{array}$ & No & Not specified & $\geq 140 / 90$ & $\geq 130-139 / 85-89$ \\
\hline $\begin{array}{l}\text { British Hypertension } \\
\text { Society }{ }^{f}\end{array}$ & No & Not specified & $\geq 160 / 100$ & $\geq 140-159 / 90-99$ \\
\hline Canadiang & No & Not specified & $\geq 140 / 90$ & $\geq 130 / 80$ \\
\hline NICE ${ }^{\text {h }}$ & No & Low-dose thiazide diuretic & $\geq 160 / 100$ & $\geq 140 / 90$ \\
\hline \multicolumn{3}{|c|}{ 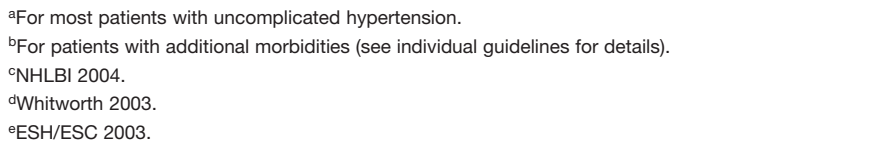 } & $\begin{array}{l}\text { 'Williams et al. } 2004 . \\
\text { '्CHEP } 2005 . \\
\text { 'nNICE } 2004 . \\
\text { SBP/DBP, systolic/diastolic blood pressure. }\end{array}$ & \\
\hline
\end{tabular}

The sequelae of hypertension can have a significant impact on patient quality of life in those who are not well controlled. Interestingly, although there is the perception of a substantial adverse impact on quality of life arising from pharmacologic treatment, this has not been borne out in the literature (Beto et al. 1992; Boissel et al. 1995; Fletcher et al. 2002; Degl'Innocenti et al. 2004).

Given the prevalence of hypertension, it follows that its economic and societal burdens are enormous. In economic terms, it is estimated that the USA spends more than \$US59.7 billion annually on the direct and indirect costs of treating hypertension (AHA 2005). Expenditures related to hypertension as well as cardiovascular complications and other diagnoses related to hypertension were estimated to be \$US108 billion in 1998 in the USA (Hodgson \& Cai 2001). In addition, the complexity of antihypertensive care, such as patient visits to ensure treatment adherence and the care issues associated with the adverse outcomes associated with uncontrolled hypertension, in an increasingly elderly Western population represents a significant societal burden.

\section{Current therapy options}

Evidence-based treatment guidelines for hypertension emphasize the importance of lifestyle modifications, including weight loss in the overweight or obese, reduction in dietary sodium intake, applying the DASH (Dietary Approaches to Stop Hypertension) diet, increasing physical activity, and limiting alcohol intake, as the first step in treatment (Whitworth 2003; NHLBI 2004; Williams et al. 2004). Lifestyle modification is indicated for all hypertensive patients; however, it rarely reduces blood pressure sufficiently and recent data underscore the importance of rapid blood pressure control (Julius et al. 2004). Therefore pharmacotherapy is generally started in most patients.

Current pharmacologic options for the treatment of hypertension include diuretics, beta blockers, ACE inhibitors, ARBs, aldosterone receptor blockers, calcium channel blockers, and alpha-1 blockers, together with various combinations of these drugs (Anon. 2003). Although there is debate over which drug to use as initial therapy, it is generally accepted that the majority of patients will not be well controlled on one drug and will require multidrug therapy. In addition, outcome studies have shown that, in general, regardless of drug choice, larger decreases in blood pressure lead to larger reductions in cardiovascular risks (Staessen et al. 2001; Turnbull 2003).

The relatively recent conclusion of major clinical trials and the publication of new systematic reviews have shed light but also created debate regarding the comparative efficacy of various antihypertensive therapies as measured by clinically relevant outcomes (ALLHAT 2002; Dahlof et al. 2002; Messerli 2003; Messerli \& Weber 2003; Wing et al. 2003; Davis et al. 2004; Julius et al. 2004). The results from some of these clinical trials together with systematic reviews (Messerli et al. 1998; Neal et al. 2000; Staessen et al. 2001; Psaty et al. 2003; Turnbull 2003) have prompted the release of new treatment guidelines from many countries and organizations. These include updated guidelines from the USA (NHLBI 2004), Canada (CHEP 2005), the WHO/International Society of Hypertension (ISH) (Whitworth 2003), the European Society of Hypertension/European Society of Cardiology (ESH/ESC 2003), the British Hypertension Society (Williams et al. 2004), and NICE (2004) (Table 2). The USA, Canadian, European, and WHO guidelines have lower overall thresholds for treatment of hypertension $(\geq 140 / 90 \mathrm{mmHg}$ except patients in special categories) compared with a threshold of $\geq 160 / 100 \mathrm{mmHg}$ in the British and NICE guidelines. In addition, the British and NICE guidelines recommend a higher threshold $(\geq 140 / 90 \mathrm{mmHg})$ for treatment of patients with additional morbidities, compared with a lower threshold $(\geq 130 / 80 \mathrm{mmHg})$ in the other guidelines. Finally, several of the guidelines encourage an overall assessment of cardiovascular risk, rather than isolated treatment of hypertension, something also emphasized in a recent review (Jackson et al. 2005). 
It is notable that the USA guidelines have established a category of "pre-hypertension," defined as 120-139/80-89 mmHg, recommending intervention with lifestyle modification, but not pharmacotherapy; individuals 65 years and older in this category are twice as likely to develop hypertension than those with lower blood pressure (NHLBI 2004). The USA, NICE, and WHO/ISH guidelines also include a highly debated endorsement of low-dose thiazide diuretics for initial therapy (see Table 2).

All the guidelines emphasize the fact that many patients need combination therapy for blood pressure control. To that end, a randomized clinical trial directly comparing two different combinations of drugs, benazapril/hydrochlorothiazide and amlodipine/benazapril, began enrolling patients in 2003 with the trial expected to conclude in 2008 (Jamerson et al. 2004). In addition, the Anglo-Scandinavian Cardiac Outcomes Trial (ASCOT), which is comparing the efficacy of a calcium channel blocker alone or in combination with an ACE inhibitor, with a beta blocker with or without a diuretic in high-risk patients (Sever et al. 2001), was stopped early because of significant reductions in moratlity with the calcium channel blocker/ACE inhibitor combination (Anon. 2005).

\section{Unmet needs}

Despite the availability of many effective, well-tolerated drugs, a significant proportion of treated hypertensive patients remain uncontrolled and face serious morbidity and mortality as a consequence.

\section{Adherence}

Adherence to treatment regimens for hypertension remains a major challenge and has been shown to be as low as $30 \%$ in some studies (Degli Eposti \& Valpiani 2004). Contributing factors for nonadherence may include patient age, drug tolerability, the largely asymptomatic nature of the disease, lack of patient education regarding adverse outcomes, and the complexities of combination drug regimens.

Various studies of interventions aimed at improving adherence, such as pharmacist and pharmacist/physician intervention, have shown some positive effects on adherence and reduction in blood pressure, including a lower visit cost per patient (Borenstein et al. 2003; Chabot et al. 2003). A review of adherence interventions found that simplification of drug dosing regimens increased

Table 3 | Aliskiren as monotherapy and in combination therapy: effects on blood pressure

\begin{tabular}{|c|c|c|c|c|c|}
\hline Level of evidence & $\begin{array}{l}\text { Once-daily drug dose } \\
\text { (mg) (n) }\end{array}$ & Duration & $\begin{array}{l}\text { Results } \pm \text { standard } \\
\text { deviation }\end{array}$ & Reference & Comment \\
\hline & & & $\begin{array}{l}\text { Mean } \downarrow \text { daytime } \\
\text { ambulatory SBP mmHg }\end{array}$ & & \\
\hline \multirow[t]{6}{*}{2} & Aliskiren 37.5 (45) & 4 weeks & $0.4 \pm 11.7$ & Stanton et al. 2003 & $\begin{array}{l}\text { No placebo arm; ANCOVA treatment effect, } \\
P=0.0002\end{array}$ \\
\hline & Aliskiren 75 (46) & & $5.3 \pm 11.3$ & & \\
\hline & Aliskiren 150 (44) & & $8 \pm 11$ & & \\
\hline & Aliskiren 300 (47) & & $11 \pm 11$ & & \\
\hline & Losartan $100(44)$ & & $10.9 \pm 13.8$ & & \\
\hline & & & $\begin{array}{l}\text { Least-squares mean } \\
\downarrow \text { SBP/DBP } \mathrm{mmHg}\end{array}$ & & \\
\hline \multirow[t]{6}{*}{2} & Aliskiren 150 (127) & 8 weeks & $11.4 \pm 1.3 / 9.3 \pm 0.8$ & Gradman et al. 2005 & $\begin{array}{l}\text { Low dose of irbesartan used; usual dose } \\
150-300 \mathrm{mg} ; P<0.001 \text { for all doses vs placebo }\end{array}$ \\
\hline & Aliskiren 300 (130) & & $15.8 \pm 1.2 / 11.8 \pm 0.8$ & & \\
\hline & Aliskiren 600 (130) & & $15.7 \pm 1.2 / 11.5 \pm 0.8$ & & \\
\hline & Irbesartan 150 (134) & & $12.5 \pm 1.2 / 8.9 \pm 0.7$ & & \\
\hline & Placebo (131) & & $5.3 \pm 1.2 / 6.3 \pm 0.8$ & & \\
\hline & & & $\begin{array}{l}\text { Absolute change in } \\
\text { mean arterial pressure } \\
4 \mathrm{~h} \text { post-dose }\end{array}$ & & \\
\hline \multirow[t]{4}{*}{2} & Aliskiren 300 (12) & $48 \mathrm{~h}$ & $4.9 \pm 5.6$ & Azizi et al. 2004 & $\begin{array}{l}\text { Study population was mildly sodium-depleted } \\
\text { normotensive healthy volunteers; } P<0.01 \text { for all } \\
\text { treatments vs placebo } 4 \mathrm{~h} \text { post-dose }\end{array}$ \\
\hline & Valsartan $160(12)$ & & $6.6 \pm 5$ & & \\
\hline & $\begin{array}{l}\text { Aliskiren } 150 / \text { Valsartan } 80 \\
\text { (12) }\end{array}$ & & $7.4 \pm 5.2$ & & \\
\hline & Placebo (12) & & $0.3 \pm 5.6$ & & \\
\hline
\end{tabular}


Table 4 | Ongoing phase II and III randomized placebo-controlled trials with aliskiren (results from these trials are not yet publicly available)

\begin{tabular}{|c|c|c|c|c|c|c|c|}
\hline Regimen & Drug dosage & n (total) & Endpoint & Duration & Inclusion & Exclusion & Phase \\
\hline Monotherapy ${ }^{a}$ & Not stated & 1064 & $\begin{array}{l}\text { Blood pressure } \\
\text { lowering }\end{array}$ & Not stated & $\begin{array}{l}\text { Mild-to-moderate } \\
\text { hypertension }\end{array}$ & Not stated & III \\
\hline $\begin{array}{l}\text { Combination therapy } \\
\text { with valsartan }^{\text {b }}\end{array}$ & Not stated & Not stated & $\begin{array}{l}\text { Blood pressure } \\
\text { lowering }\end{array}$ & Not stated & $\begin{array}{l}\text { Mild-to-moderate } \\
\text { hypertension }\end{array}$ & Not stated & II \\
\hline Monotherapyc & Not stated & 496 & $\begin{array}{l}\text { Reduction in level } \\
\text { of protein in urine }\end{array}$ & Not stated & $\begin{array}{l}\text { Hypertension; elevated } \\
\text { serum protein levels; } \\
\text { confirmed type } 2 \text { diabetes }\end{array}$ & $\begin{array}{l}\text { Certain diseases; } \\
\text { uncontrolled diabetes; } \\
\text { type } 1 \text { diabetes }\end{array}$ & II \\
\hline \multicolumn{8}{|c|}{$\begin{array}{l}\text { aManufacturer press release, January 21, } 2005 . \\
\text { bManufacturer press release, January 21, } 2005 .\end{array}$} \\
\hline
\end{tabular}

adherence between 8 and $19.6 \%$ (seven of nine studies); motivational strategies increased adherence up to $23 \%$ (10 of 24 studies); and interventions using multiple techniques increased adherence from 5 to $41 \%$ (eight of 18 studies) (Schroeder et al. 2004). The review concluded that reducing the number of daily doses of medication seemed to be effective, and, while the motivational and more complex interventions appeared somewhat effective, there was a need for more carefully designed studies to gauge the true impact of such strategies.

\section{Tolerability}

In addition to education and the complexities of antihypertensive treatment regimens, treatment-related adverse effects may contribute to poor adherence rates (Caro et al. 1999). While some antihypertensive medications are very well tolerated, particularly the ARBs, like all drugs antihypertensive therapies have adverse effects that limit their utility in some patients (Anon. 2003), particularly in specific patient populations. Therefore improvement in tolerability remains a goal of future drug development.

\section{Multidrug therapy}

A further unmet challenge in the pharmacotherapy of hypertension is the reality that most patients need treatment with more than one antihypertensive drug, which may lead to additional adverse events and a further decrease in adherence. This is particularly true in patients with chronic kidney disease who often need more than two drugs to control their hypertension. Therefore a drug that can be used in monotherapy remains a goal of future drug development, although it is questionable whether it can be realistically achieved.

Given these unmet needs, although clinical outcome trials ideally need to measure long-term mortality, they should first focus on the extent of blood pressure reduction (which correlates well with longterm outcomes), tolerability, and adherence to therapy.

Recent clinical trials and systematic reviews of trials have emphasized that the magnitude of blood pressure reduction is the most important contributor to decreasing morbidity and mortality in patients with hypertension. Blood pressure is therefore an acceptable surrogate outcome in preliminary short-term trials.

\section{Outcomes achieved with aliskiren in clinical development}

Phase II trials of aliskiren in patients with uncomplicated mild-tomoderate hypertension are complete. The outcomes studied include blood pressure reduction with use in monotherapy or in combination with ARBs (pilot study only), and tolerability.

\section{Blood pressure reduction with monotherapy}

Aliskiren entered phase II trials for treatment of mild-to-moderate hypertension following pilot studies that demonstrated treatmentrelated reduction in angiotensin II levels (Hollenberg 2002; Nussberger et al. 2002). There is now good phase II evidence that aliskiren reduces blood pressure significantly compared with placebo and that it is as effective as losartan and irbesartan (Table 3). Aliskiren 150 or 300 mg once daily were as effective as an ARB (losartan $100 \mathrm{mg}$ or irbesartan $150 \mathrm{mg}$ ) and significantly more effective than placebo in reducing systolic and diastolic blood pressure (Stanton 2003; Gradman et al. 2005).

This evidence from phase II trials is being verified in phase III trials, including a trial outlined in Table 4, which should provide more level 2 evidence of the effectiveness of aliskiren as monotherapy on blood pressure reduction in patients with mild-to-moderate hypertension. Early results from these trials are not yet publicly available.

\section{Combination therapy with ARBs}

As most patients will require combination therapy it will be important to evaluate the use of aliskiren in combination with other antihypertensives. A small double-blind, placebo-controlled, pilot study in 12 healthy, mildly sodium-depleted normotensive volunteers examined the blood pressure lowering effects of single doses of aliskiren $300 \mathrm{mg}$, valsartan $160 \mathrm{mg}$, a lower-dose combination of the two drugs (aliskiren $150 \mathrm{mg}$ and valsartan $80 \mathrm{mg}$ ), and placebo over a 48-h period (Azizi et al. 2004) (see Table 3). Four hours after treatment the lower-dose combination treatment was as effective as the higher doses of each individual drug and significantly lowered mean arterial pressure compared with placebo. It should be emphasized that this was a pilot study performed in normotensive volunteers. 
To expand upon these preliminary results and to attempt to provide evidence for use of aliskiren in combination therapy, a phase II trial in patients with hypertension is examining the effects of treatment with aliskiren and valsartan on blood pressure reduction (see Table 4).

\section{Tolerability}

The adverse effect profiles of current antihypertensive drugs can, in part, be attributed to their sites of action or influence on downstream mediators. For example, ACE affects the metabolism of bradykinin and increases circulating and tissue concentrations of substance $P$ which, while contributing to the blood pressure lowering effect of ACE inhibitors, may also cause troublesome adverse effects including cough and angioedema that limit their clinical use (Sunman \& Sever 1993). Furthermore, blocking the RAS with ARBs inhibits activation at the AT- 1 subtype of angiotensin II receptors, but since angiotensin II production is not blocked with these drugs, it can still act at other sites. Aliskiren was developed for its specificity and high affinity for renin thereby minimizing its potential to act at alternative sites and theoretically minimizing potential adverse effects. There are, however, local renin systems where renin inhibition would not be desirable. For example, the potential role of renin in the uterus may limit aliskiren's use to nonpregnant women (Shaw et al. 1989).

Evidence to date shows that aliskiren has a favorable adverseeffect profile. Adverse effects associated with aliskiren were similar in severity and incidence to those reported in patients treated with losartan or irbesartan. The most commonly reported adverse effects were fatigue or weakness, gastrointestinal disorders, dizziness, and headache (Stanton 2003; Gradman et al. 2005). Of those patients in whom a serious adverse event occurred or who experienced an adverse event leading to withdrawal from the study, one of two in the $37.5 \mathrm{mg}$ aliskiren treatment arm, three of three in the $75 \mathrm{mg}$ aliskiren arm, two of three in the $300 \mathrm{mg}$ aliskiren arm, and one of three in the $100 \mathrm{mg}$ losartan treatment arm had events that may have been related to drug treatment; no patients in the $150 \mathrm{mg}$ aliskiren arm had serious adverse events (Stanton 2003). In another study, no serious adverse events were reported in patients treated with aliskiren although one patient in the $600 \mathrm{mg}$ treatment arm stopped treatment because of elevated serum glutamicoxaloacetate transaminase (SGOT) and bilirubin and increased diastolic blood pressure (Gradman et al. 2005). Furthermore, there is evidence that aliskiren does not interact with warfarin (Dieterle et al. 2004), a commonly co-prescribed drug particularly in elderly patients with stroke risk, thus widening the proportion of patients for whom aliskiren may be an option.

\section{Adherence}

Adherence to antihypertensive therapy is a complex issue influenced by many variables. One important factor is drug tolerability; drugs associated with fewer adverse events have higher adherence and persistence rates (Gerth 2002; Marentette et al. 2002).

There is preliminary evidence from one study that adherence to aliskiren therapy is high, averaging $>95 \%$ in patients treated with aliskiren $(37.5,75,150$, or $300 \mathrm{mg}$ once daily) or losartan (100 mg once daily) for 4 weeks (Stanton 2003). These adherence measures are not sufficient, however, and more studies are needed.

\section{Resource utilization}

The economic burden of treating hypertension is estimated to be almost \$US60 billion per year in the USA (AHA 2005). It is estimated that the direct costs of drug therapy alone account for a large proportion (about 50\%) of the direct health costs of treating hypertension (AHA 2005) and therefore cost-effectiveness ratios are highly dependent on the choice of drug.

However, drug acquisition cost is just one component for consideration when evaluating the economic impact of treating patients with hypertension. For example, studies have shown that it is more cost-effective to treat more severe hypertension compared with less severe disease, to treat older versus younger patients, and to treat men versus women (Kawachi \& Malcolm 1991; Stason 1991).

There is no economic evidence for the use of aliskiren in the treatment of hypertension. Economic studies show thiazide diuretics are currently the most cost-effective agents because of their low acquisition cost (Ramsey et al. 1999; Fischer \& Avorn 2004) and aliskiren, due to the complexity of the manufacturing process, is likely to have high acquisition costs. Nevertheless, there is clearly a role for other commonly used drug classes, including ACE inhibitors, ARBs, and calcium channel blockers in the management of patients with hypertension based on better clinical outcomes and patient preferences, e.g. tolerability. Cost-benefit and cost-effectiveness comparisons of aliskiren with these drug classes and in specific patient groups would therefore be welcome. Furthermore, evidence related to any total cost-benefit of treatment with aliskiren that included indirect costs, benefits in terms of primary outcome prevention, and tolerability would provide a more comprehensive view of its potential clinical utility.

\section{Patient group/population}

To date, aliskiren has been studied in completed phase II trials and ongoing phase III trials in patients with uncomplicated mild-tomoderate hypertension. The existing evidence suggests that aliskiren effectively lowers blood pressure and is associated with good tolerability in this patient population.

However, hypertension is associated with many other comorbid conditions and aliskiren is currently in phase II trials for treatment of some of these populations, including diabetic nephropathy. Treatment of hypertensive patients with and without diabetes with ACE inhibitors or ARBs, inhibitors of the RAS, has been shown to reduce progression to macroalbuminuria, reduce albuminuria, and slow the progression of diabetic nephropathy independent of their effects on arterial blood pressure (Lewis et al. 1993; GISEN Group 1997; Brenner et al. 2001; Lewis et al. 2001; Wright et al. 2002).

Intraglomerular hypertension is thought to be a causative factor in the progression of diabetic nephropathy as well as other chronic nephropathies. Angiotensin II leads to constriction of afferent and efferent glomerular arterioles; these effects are more prominent in the efferent arteriole and the net result is an increase in glomerular perfusion pressure. Both ACE inhibitors and ARBs, by inhibiting angiotensin II production/action, decrease glomerular pressure (Braam \& Koomans 1996). Renin inhibitors including aliskiren inhibit angiotensin II more completely than ARBs and ACE 
inhibitors and therefore would be expected to more effectively limit glomerular hypertension.

Indeed, it had been previously demonstrated, in earlier attempts at renin inhibitor drug development, that these drugs cause renal vasodilatory responses that are $50 \%$ greater than those seen with ACE inhibitors (Hollenberg \& Fisher 1995). Aliskiren could therefore be more effective than existing therapies in treatment of diabetic nephropathy in patients with or without hypertension, and treatment of chronic kidney disease in patients with or without diabetes, but to date there is no clinical evidence of its efficacy in these patient populations. Furthermore, it is unclear whether more complete angiotensin II blockade will lead to clinically relevant incremental benefits. In addition glomerular filtration rate (GFR) is a function of perfusion pressure and more complete blockade of angiotensin II could lead to excessive decreases in GFR thereby limiting the drug's utility in patients with chronic kidney disease. This is an important topic that warrants further studies.

The effectiveness of aliskiren in other high-risk patient populations, such as those with severe hypertension or other cardiovascular risk factors (chronic heart failure, previous myocardial infarction, stroke, etc.) is unknown. Its effectiveness in other races (particularly African-Americans), or special populations, such as the elderly and children, also remains to be determined.

\section{Clinical potential}

The existing clinical and economic burden of hypertension underscores the significant needs that remain regarding hypertension therapy. In an attempt to address some of these needs, aliskiren was developed using rational drug design principles. These principles indicate that theoretically aliskiren should be as effective as current treatments, but with tolerability and adherence advantages.

There is strong preliminary evidence that aliskiren as monotherapy given once daily is effective at reducing blood pressure in patients with mild-to-moderate hypertension. In addition, there is some evidence that aliskiren is comparable in efficacy to the ARBs losartan and irbesartan. Clinical trials to date have also shown that aliskiren is well tolerated, with adverse effect and adherence rates comparable to ARBs. A good tolerability profile together with oncedaily administration may be expected to positively influence adherence and quality of life, both of which can be significant barriers to effective disease management in patients with hypertension. Phase III trials are currently underway, which may attempt to confirm these phase II data.

For patients whose blood pressure can be controlled with singleagent therapy, aliskiren may offer another well-tolerated, effective alternative, but most patients with hypertension eventually need a second antihypertensive drug. There is some evidence that aliskiren combined with an ARB is effective in reducing blood pressure. To date, one small, short-term (48 h) published pilot study has shown that aliskiren effectively lowers blood pressure when used in combination with the ARB valsartan in normotensive individuals. Phase II trials in patients with mild-to-moderate hypertension are currently underway (see Table 4).
In addition, if current phase II trials and future phase III trials in patients with diabetic nephropathy provide clinical evidence of its effectiveness, then aliskiren might prove to be of significant benefit in these patients. Further evidence will therefore be needed to demonstrate aliskiren's effectiveness in this and other patient groups, such as those with severe hypertension, the elderly, and those with other risk factors, e.g. chronic heart failure and chronic kidney disease.

There is strong phase II evidence that aliskiren effectively lowers blood pressure and blood pressure reduction is a valid predictor of reduced mortality and cardiovascular events. On this basis, although there are currently no long-term outcome data with aliskiren on its effects on mortality and/or major cardiovascular events, the evidence regarding its effect on blood pressure lowering suggests that it is likely to be effective in reducing mortality.

Evidence suggests that treatment with the other RAS inhibitors, ACE inhibitors, or ARBs, can have positive cardiovascular effects that are independent of blood pressure control. Therefore aliskiren has the potential to have similar effects, acting as it does on the first step in the RAS pathway, effectively blocking the production of angiotensin II.

The precise economic impact of aliskiren is still unclear. However, if its good tolerability profile and effectiveness are confirmed in phase III studies, aliskiren may be a cost-effective option in the treatment of hypertension, especially in patient populations where it may prove to have a therapeutic advantage, e.g. patients with diabetic nephropathy.

In summary, the available outcomes evidence for aliskiren from phase II trials is encouraging and shows that it is effective in patients with mild-to-moderate hypertension in monotherapy and possibly as effective an ARB. Moreover, if the evidence from phase II and III trials of aliskiren in combination therapy demonstrates an antihypertensive effect of similar magnitude to existing combination drugs, this in addition to its good tolerability profile and once-daily dosing will support its use.

\section{References}

Agarwal A, Williams GH, Fisher NDL. Genetics of human hypertension. Trends Endocrinol Metab. 2005;16(3):127-133.

AHA (American Heart Association). 2005 heart and stroke statistical update. www.americanheart.org/statistics. Accessed March 3, 2005.

ALLHAT Officers and Coordinators for the ALLHAT Collaborative Research Group. The Antihypertensive and Lipid-Lowering Treatment to Prevent Heart Attack Trial. Major outcomes in moderately hypercholesterolemic, hypertensive patients randomized to pravastatin vs usual care: the Antihypertensive and Lipid-Lowering Treatment to Prevent Heart Attack Trial (ALLHAT-LLT). JAMA.

2002;288(23):2998-3007.

Anon. Drugs for hypertension. Treat Guidel Med Lett. 2003;1(6):33-40.

Anon. Has recent evidence changed the choice of BP-lowering agents? MeReC Extra. 2005; issue 16.

Azizi M, Menard J, Bissery A, Guyenne TT, Bura-Riviere A, Vaidyanathan S, Camisasca RP. Pharmacologic demonstration of the synergistic effects of a combination of the renin inhibitor aliskiren and the AT1 receptor antagonist valsartan on the angiotensin II-renin feedback interruption. J Am Soc Nephrol. 2004;15(12):3126-3133.

Bakris GL, Williams M, Dworkin L, et al. Preserving renal function in adults with hypertension and diabetes: a consensus approach. National Kidney Foundation 
Hypertension and Diabetes Executive Committees Working Group. Am J Kidney Dis. 2000;36(3):646-661.

Beto JA, Bansal VK. Quality of life in treatment of hypertension. A metaanalysis of clinical trials. Am J Hypertens. 1992;5(3):125-133.

Boissel JP, Collet JP, Lion L, et al. A randomized comparison of the effect of four antihypertensive monotherapies on the subjective quality of life in previously untreated asymptomatic patients: field trial in general practice. The OCAPI Study Group. Optimiser le Choix d'un Anti-hypertenseur de Premiere Intention. J Hypertens. 1995;13(9):1059-1067.

Borenstein JE, Graber G, Saltiel E, et al. Physician-pharmacist comanagement of hypertension: a randomized, comparative trial. Pharmacotherapy. 2003;23(2):209-216.

Braam B, Koomans HA. Renal responses to antagonism of the renin-angiotensin system. Curr Opin Nephrol Hypertens. 1996;5:89.

Brenner BM, Cooper ME, de Zeeuw D, et al.; RENAAL Study Investigators. Effects of losartan on renal and cardiovascular outcomes in patients with type 2 diabetes and nephropathy. N Engl J Med. 2001;345(12):861-869.

Caro JJ, Speckman JL, Salas M, Raggio G, Jackson JD. Effect of initial drug choice on persistence with antihypertensive therapy: the importance of actual practice data. CMAJ. 1999;160(1):41-46.

Chabot I, Moisan J, Gregoire JP, Milot A. Pharmacist intervention program for control of hypertension. Ann Pharmacother. 2003;37(9):1186-1193.

CHEP (Canadian Hypertension Education Program). 2005 Canadian Hypertension Education Program Recommendations: the bottom line version. Available at: http://www.hypertension.ca/recommendations_2005/execsummary2005.pdf. Accessed February 8, 2005.

Cooper RS, Wolf-Maier K, Luke A, et al. An international comparative study of blood pressure in populations of European vs. African descent. BMC Med. 2005;3(2) doi:10.1186/1741-7015-3-2. Available online (open access) at: http://www.biomedcentral.com/content/pdf/1741-7015-3-2.pdf

Dahlof B, Devereux RB, Kjeldsen SE, et al.; LIFE Study Group. Cardiovascular morbidity and mortality in the Losartan Intervention For Endpoint reduction in hypertension study (LIFE): a randomised trial against atenolol. Lancet. 2002;359(9311):995-1003.

Davis BR, Furberg CD, Wright JT Jr, Cutler JA, Whelton P; ALLHAT Collaborative Research Group. ALLHAT: setting the record straight. Ann Intern Med. 2004;141(1):39-46.

Degli Esposti L, Valpiani G. Pharmacoeconomic burden of undertreating hypertension. PharmacoEconomics. 2004;22(14):907-928.

Degl'Innocenti A, Elmfeldt D, Hofman A, et al. Health-related quality of life during treatment of elderly patients with hypertension: results from the Study on COgnition and Prognosis in the Elderly (SCOPE). $J$ Hum Hypertens. 2004;18(4):239-245.

Dieterle W, Corynen S, Mann J. Effect of the oral renin inhibitor aliskiren on the pharmacokinetics and pharmacodynamics of a single dose of warfarin in healthy subjects. Br J Clin Pharmacol. 2004;58(4):433-436.

ESH/ESC (European Society of Hypertension-European Society of Cardiology Guidelines Committee). 2003 European Society of Hypertension-European Society of Cardiology guidelines for the management of arterial hypertension. $J$ Hypertens. 2003;21(6):1011-1053.

Fischer MA, Avorn J. Economic implications of evidence-based prescribing for hypertension: can better care cost less? JAMA. 2004;291(15):1850-1856.

Fisher ND, Hollenberg NK. Is there a future for renin inhibitors? Expert Opin Invest Drugs. 2001;10(3):417-426.

Fletcher AE, Bulpitt CJ, Thijs L, et al.; Syst-Eur Trial Investigators. Quality of life on randomized treatment for isolated systolic hypertension: results from the SystEur Trial. J Hypertens. 2002;20(10):2069-2079.

Gerth WC. Compliance and persistence with newer antihypertensive agents. Curr Hypertens Rep. 2002:4(6):424-433.

GISEN Group (Gruppo Italiano di Studi Epidemiologici in Nefrologia). Randomised placebo-controlled trial of effect of ramipril on decline in glomerular filtration rate and risk of terminal renal failure in proteinuric, non-diabetic nephropathy. Lancet. 1997;349(9069):1857-1863.
Gradman AH, Schmieder RE, Lins RL, Nussberger J, Chiang Y, Bedigian MP. Aliskiren, a novel orally effective renin inhibitor, provides dose-dependent antihypertensive efficacy and placebo-like tolerability in hypertensive patients. Circulation. 2005;111(8):1012-1018

Hodgson TA, Cai L. Medical care expenditures for hypertension, its complications, and its comorbidities. Med Care. 2001;39(6):599-615.

Hollenberg NK. Angiotensin II suppression in humans by the orally active renin inhibitor aliskiren (SPP100). Comparison with enalapril. Curr Hypertens Rep. 2002;4(4):269-270.

Hollenberg NK, Fisher ND. Renal circulation and blockade of the reninangiotensin system. Is angiotensin-converting enzyme inhibition the last word? Hypertension. 1995;26(4):602-609.

Jackson R, Lawes CM, Bennett DA, Milne RJ, Rodgers A. Treatment with drugs to lower blood pressure and blood cholesterol based on an individual's absolute cardiovascular risk. Lancet. 2005;365(9457):434-441.

Jamerson KA, Bakris GL, Wun CC, et al. Rationale and design of the avoiding cardiovascular events through combination therapy in patients living with systolic hypertension (ACCOMPLISH) trial: the first randomized controlled trial to compare the clinical outcome effects of first-line combination therapies in hypertension. Am J Hypertens. 2004;17(9):793-801.

Julius S, Kjeldsen SE, Weber M, et al.; VALUE trial group. Outcomes in hypertensive patients at high cardiovascular risk treated with regimens based on valsartan or amlodipine: the VALUE randomised trial. Lancet. 2004;363(9426):2022-2031.

Kawachi I, Malcolm LA. The cost-effectiveness of treating mild-to-moderate hypertension: a reappraisal. J Hypertens. 1991;9(3):199-208.

Kearney PM, Whelton M, Reynolds K, Muntner P, Whelton PK, He J. Global burden of hypertension: analysis of worldwide data. Lancet. 2005;365(9455):217-223.

Lewis EJ, Hunsicker LG, Bain RP, Rohde RD. The effect of angiotensinconverting-enzyme inhibition on diabetic nephropathy. The Collaborative Study Group. N Engl J Med. 1993;329(20):1456-1462.

Lewis EJ, Hunsicker LG, Clarke WR, et al.; Collaborative Study Group. Renoprotective effect of the angiotensin-receptor antagonist irbesartan in patients with nephropathy due to type 2 diabetes. $N$ Engl $J$ Med. 2001;345(12):851-860.

Marentette MA, Gerth WC, Billings DK, Zarnke KB. Antihypertensive persistence and drug class. Can J Cardiol. 2002;18(6):649-656.

Messerli FH. ALLHAT or the soft science of the secondary end point. Ann Intern Med. 2003;139(9):777-780.

Messerli FH, Weber MA. ALLHAT-all hit or all miss? Key questions still remain. Am J Cardiol. 2003;92(3):280-281.

Messerli FH, Grossman E, Goldbourt U. Are beta-blockers efficacious as first-line therapy for hypertension in the elderly? A systematic review. JAMA. 1998;279(23):1903-1907.

NCHS (National Center for Health Statistics. Health), United States, 2004 with Chartbook on Trends in the Health of Americans. Hyattsville, MD. 2004, p.238. Available at: http://www.cdc.gov/nchs/data/hus/hus04.pdf. Accessed on February 10, 2005.

NHLBI (National Heart, Lung, and Blood Institute). Complete Report: The Seventh Report of the Joint National Committee on Prevention, Detection, Evaluation, and Treatment of High Blood Pressure. Bethesda, MD: National Institutes of Health; 2004. Publication 04-5230.

NICE (National Institute for Health and Clinical Excellence). CG18 Hypertension (persistently high blood pressure) in adults - Full guideline. Essential hypertension: managing adult patients in primary care. Available at: http://www.nice.org.uk/pdf/CG018fullguideline.pdf. Accessed February 8, 2004.

Neal B, MacMahon S, Chapman N; Blood Pressure Lowering Treatment Trialists' Collaboration. Effects of ACE inhibitors, calcium antagonists, and other bloodpressure-lowering drugs: results of prospectively designed overviews of randomised trials. Blood Pressure Lowering Treatment Trialists' Collaboration. Lancet. 2000;356(9246):1955-1964. 
Nussberger J, Wuerzner G, Jensen C, Brunner HR. Angiotensin II suppression in humans by the orally active renin inhibitor aliskiren (SPP100): comparison with enalapril. Hypertension. 2002;39(1):E1-8.

Psaty BM, Lumley T, Furberg CD, et al. Health outcomes associated with various antihypertensive therapies used as first-line agents: a network meta-analysis. JAMA. 2003;289(19):2534-2544.

Ramsey SD, Neil N, Sullivan SD, Perfetto E. An economic evaluation of the JNC hypertension guidelines using data from a randomized controlled trial. Joint National Committee. J Am Board Fam Pract. 1999;12(2):105-114.

Rongen GA, Lenders JW, Smits P, Thien T. Clinical pharmacokinetics and efficacy of renin inhibitors. Clin Pharmacokinet. 1995;29(1):6-14.

Schroeder K, Fahey T, Ebrahim S. Interventions for improving adherence to treatment in patients with high blood pressure in ambulatory settings. Cochrane Database Syst Rev. 2004;(2):CD004804.

Sever PS, Dahlof B, Poulter NR, et al. Rationale, design, methods and baseline demography of participants of the Anglo-Scandinavian Cardiac Outcomes Trial. ASCOT investigators. J Hypertens. 2001;19(6):1139-1147.

Shaw KJ, Do YS, Kjos S, et al. Human decidua is a major source of renin. $J$ Clin Invest. 1989;83(6):2085-2092.

Staessen JA, Wang JG, Thijs L. Cardiovascular protection and blood pressure reduction: a meta-analysis. Lancet. 2001;358(9290):1305-1315.

Stanton A. Therapeutic potential of renin inhibitors in the management of cardiovascular disorders. Am J Cardiovasc Drugs. 2003;3(6):389-394.

Stanton A, Jensen C, Nussberger J, O'Brien E. Blood pressure lowering in essential hypertension with an oral renin inhibitor, aliskiren. Hypertension. 2003;42(6):1137-43.

Stason WB. Opportunities to improve the cost-effectiveness of treatment for hypertension. Hypertension. 1991;18(3 Suppl):I161-I166.

Sunman W, Sever PS. Non-angiotensin effects of angiotensin-converting enzyme inhibitors. Clin Sci (Lond). 1993;85(6):661-670.

Touyz RM. Molecular and cellular mechanisms in vascular injury in hypertension: role of angiotensin II. Curr Opin Nephrol Hypertens. 2005;Mar;14(2):125-131.

Turnbull F; Blood Pressure Lowering Treatment Trialists' Collaboration. Effects of different blood-pressure-lowering regimens on major cardiovascular events: results of prospectively-designed overviews of randomised trials. Lancet. 2003;362(9395):1527-1535.
Vasan RS, Beiser A, Seshadri S, Larson MG, Kannel WB, D'Agostino RB, Levy D. Residual lifetime risk for developing hypertension in middle-aged women and men: The Framingham Heart Study. JAMA. 2002;287(8):1003-1010.

Whitworth JA; World Health Organization, International Society of Hypertension Writing Group. 2003 World Health Organization (WHO)/International Society of Hypertension (ISH) statement on management of hypertension. $J$ Hypertens. 2003;21(11):1983-1992.

WHO (World Health Organization). The World Health Report 2002: Reducing Risks, Promoting Healthy Life. Geneva, Switzerland: WHO; 2002.

Williams B, Poulter NR, Brown MJ, et al.; British Hypertension Society. Guidelines for management of hypertension: report of the fourth working party of the British Hypertension Society, 2004-BHS IV. J Hum Hypertens. 2004;18(3):139-185.

Wing LM, Reid CM, Ryan P, et al.; Second Australian National Blood Pressure Study Group. A comparison of outcomes with angiotensin-converting-enzyme inhibitors and diuretics for hypertension in the elderly. $N$ Engl $J$ Med. 2003;348(7):583-592.

Wolf-Maier K, Cooper RS, Banegas JR, et al. Hypertension prevalence and blood pressure levels in 6 European countries, Canada, and the United States. JAMA. 2003;289(18):2363-2369.

Wolf-Maier K, Cooper RS, Kramer H, et al. Hypertension treatment and control in five European countries, Canada, and the United States. Hypertension. 2004;43(1):10-17. Epub 2003 Nov 24.

Wolny A, Clozel JP, Rein J, et al. Functional and biochemical analysis of angiotensin II-forming pathways in the human heart. Circ Res. 1997;80(2):219-227.

Wood JM, Maibaum J, Rahuel J, et al. Structure-based design of aliskiren, a novel orally effective renin inhibitor. Biochem Biophys Res Commun. 2003;308(4):698-705.

Wright JT Jr, Agodoa L, Contreras G, et al.; African American Study of Kidney Disease and Hypertension Study Group. Successful blood pressure control in the African American Study of Kidney Disease and Hypertension. Arch Intern Med. 2002;162(14):1636-1643.

Correspondence: Doris Peter, Core Medical Publishing, 445 Hamilton Avenue, Suite 1102, White Plains, New York, NY 10601, USA or at editor@coreevidence.com 